\title{
Oxygen Supply and Energy-yielding Substrates for Nitrogen Fixation (Acetylene Reduction) by Bacteroid Preparations
}

\author{
By J. C. TRINCHANT, A. M. BIROT AND J. RIGAUD* \\ Laboratoire de Biologie végétale, Faculté des Sciences et des Techniques, Parc Valrose, \\ 06034 Nice Cedex, France
}

(Received 24 October 1980; revised 5 January 1981)

\begin{abstract}
Sucrose and glucose supported acetylene reduction by bacteroids extracted from Frenchbean, soybean and pea root nodules in the presence of low $\mathrm{O}_{2}$ concentrations in experiments carried out with or without a gas phase, but not under $\mathrm{O}_{2}$ tensions usually able to support acetylene reduction with succinate. Addition of leghaemoglobin to the bacteroid suspensions allowed maximum rates of ethylene formation at very low $\mathrm{O}_{2}$ concentrations ( 1 to $5 \mathrm{nM}$ ) when sucrose or glucose was present in assays with no gas phase. Stimulation of bacteroid $\mathrm{O}_{2}$ consumption was lower with these carbohydrates than with succinate for a similar acetylene reduction activity. This low $\mathrm{O}_{2}$ uptake provided $\mathrm{O}_{2}$ steady-state conditions in gas phase experiments. The optimal $\mathrm{O}_{2}$ tension required for bacteroid acetylene reduction was lower when nodule age increased.
\end{abstract}

\section{INTRODUCTION}

Bacteroids of legume root nodules have an absolute $\mathrm{O}_{2}$ requirement for $\mathrm{N}_{2}$ fixation (Bergersen, 1971), since respiration provides both energy and electron flow for nitrogenase activity. Anaerobic preparations of bacteroids were able to reduce ${ }^{15} \mathrm{~N}_{2}$ in the presence of $\mathrm{O}_{2}$ tensions lower than 10\%, which avoid nitrogenase inactivation (Bergersen, 1967). Energy-yielding substrates added to incubations enhanced $\mathrm{N}_{2}$ fixation by increasing the respiration rate of bacteroids, and organic acids such as succinate and fumarate were particularly efficient (Bergersen \& Turner, 1967). In contrast, glucose and sucrose were generally considered as completely inefficient under the same conditions (Bergersen, 1974). Using French-bean bacteroids, we recently observed the ability of glucose to act as an energy-yielding substrate for acetylene reduction when low $\mathrm{O}_{2}$ tensions were used (Trinchant \& Rigaud, 1979). Since sucrose and glucose are the main products translocated to the root nodules (Bach et al., 1958; Streeter \& Bosler, 1976; Singh et al., 1980), whereas succinate has not been detected in the host cells (Antoniw \& Sprent, 1978), it was of interest to investigate the role of these sugars in $\mathrm{N}_{2}$ fixation.

In this paper we describe acetylene reduction in the presence of sucrose and glucose, in comparison with succinate, by bacteroids isolated from different legumes. An $\mathrm{O}_{2}$ concentration-dependent efficiency of these substrates was demonstrated in experiments carried out with a gas phase, or with no gas phase and leghaemoglobin as $\mathrm{O}_{2}$ carrier.

\section{METHODS}

Production of nodules and preparation of bacteroids. Nodules were produced on the roots of French-bean (Phaseolus vulgaris L. cv. Contander) inoculated with Rhizobium phaseoli strain 9-6, on soybean (Glycine max Merr. cv. Altona) inoculated with Rhizobium japonicum strain 1809 , and on pea (Pisum sativum L. cv. Centurion) inoculated with Rhizobium leguminosarum strain FH16. Plants were grown in a glasshouse as described previously (Rigaud \& Puppo, 1975). 
Bacteroids were prepared anaerobically from 25 to $30 \mathrm{~g}$ (fresh wt) of French-bean and soybean nodules, or from 15 to $18 \mathrm{~g}$ (fresh wt) of pea nodules, by the method of Bergersen \& Turner (1973). After washing in $40 \mathrm{ml}$ phosphate buffer $(50 \mathrm{mM}, \mathrm{pH} 7.4)$ containing sucrose $(0.3 \mathrm{M})$, bacteroids were resuspended in phosphate buffer ( $25 \mathrm{mM}, \mathrm{pH} 7.4$ ) to give a final concentration of about $40 \mathrm{mg}$ dry wt $\mathrm{ml}^{-1}$.

Leghaemoglobin. The red supernatant obtained by centrifugation of nodule homogenates was purified according to Appleby (1969), using the conditions described by Puppo \& Rigaud (1975). Oxyleghaemoglobin, prepared after $\mathrm{Na}_{2} \mathrm{~S}_{2} \mathrm{O}_{4}$ treatment and chromatography on a $25<2.5 \mathrm{~cm}$ column of Sephadex G-15 (Wittenberg et al., 1974), was concentrated to 400 to $600 \mu \mathrm{M}$ over an Amicon UM10 membrane; $1 \mathrm{ml}$ samples were stored in liquid $\mathrm{N}_{2}$ until used (Bergersen \& Turner, 1979). Leghaemoglobin concentrations were determined from pyridine haemochromogen assays (Bergersen et al., 1973).

Measurement of $\mathrm{O}_{2}$ concentration. For low concentrations of dissolved $\mathrm{O}_{2}, \mathrm{O}_{2}$ consumption by bacteroids was assayed by the deoxygenation of oxyleghaemoglobin measured at $576 \mathrm{~nm}$ (the $\alpha$ peak of the oxyhaemoprotein) and $562 \mathrm{~nm}$ (the trough between the $\alpha$ and $\beta$ peaks) (Bergersen \& Turner, 1975, 1979). Assays (4 ml) were made in glass cuvettes ( $10 \mathrm{~mm}$ light path) closed with rubber serum stoppers. The cuvettes were flushed with Ar and then completely filled with the reaction solution which contained 50 to $100 \mu \mathrm{M}$-leghaemoglobin and dissolved $\mathrm{O}_{2}$. Bacteroids ( $1 \mathrm{mg}$ dry wt) were added using a microsyringe and the cuvettes, containing two glass beads, were vigorously shaken. The reaction $(15 \mathrm{~min}$ ) was followed by recording, during $1 \mathrm{~min}$, the absorbance at 562 or 576 $\mathrm{nm}$ alternately in a Varian Techtron spectrophotometer (model 635) with a temperature-controlled sample chamber maintained at $25^{\circ} \mathrm{C}$. The determination of free dissolved $\mathrm{O}_{2}$ concentrations from the oxygenation state of leghaemoglobin and the constants used in the calculations were as described by Bergersen \& Turner (1979).

$\mathrm{O}_{2}$ concentration was also determined in experiments carried out with a gas phase in $24 \mathrm{ml}$ rubber-capped vials containing $2 \mathrm{ml}$ reaction medium. At intervals, reactions were terminated by injecting $0.1 \mathrm{ml}$ of $2.5 \mathrm{M}-\mathrm{HCl}$. Samples $(0.2 \mathrm{ml})$ were then transferred, under $\mathrm{Ar}$, by microsyringe to an $\mathrm{O}_{2}$ electrode chamber containing $1.8 \mathrm{ml}$ Ar-saturated phosphate buffer ( $25 \mathrm{mM}, \mathrm{pH}$ 7.4). The $\mathrm{O}_{2}$ electrode (Rank Bros., Bottisham, Cambs.) was equipped with an amplifier and a recorder (Bergersen \& Turner, 1975).

Nitrogenase activity. Incubations with a gas phase were performed in duplicate; bacteroid nitrogenase activity was measured by the acetylene reduction technique (Hardy et al., 1968), using the conditions previously described (Rigaud, 1976). Experiments with no gas phase were done in triplicate in glass cuvettes, using a reaction medium equilibrated with a gas mixture containing 15 to $20 \%(\mathrm{v} / \mathrm{v})$ acetylene (120 to $140 \mathrm{mmHg})$. At 5 min intervals during $\mathrm{O}_{2}$ consumption (15 min), samples were slowly withdrawn from the reaction mixture with a syringe and injected into evacuated $15 \mathrm{ml}$ 'Venoject' tubes (Bergersen \& Turner, 1975). The evolved gas was analysed by gas chromatography and the amount of ethylene was determined.

\section{RES ULTS}

\section{Acetylene reduction by bacteroids in the presence of glucose and sucrose}

Experiments were carried out with a gas phase containing different partial pressures of $\mathrm{O}_{2}$. With French-bean bacteroids, nitrogenase activity initially increased with increasing $p \mathrm{O}_{2}$ when glucose or sucrose was added (Fig. $1 a$ ). The activity reached an optimum at a $p \mathrm{O}_{2}$ of 20 to $25 \mathrm{mmHg}$ and then sharply declined. No acetylene reduction was observed with $\mathrm{O}_{2}$ tensions higher than $40 \mathrm{mmHg}$. In contrast, with succinate, a usual substrate for bacteroid incubations, acetylene reduction activity increased linearly with $\mathrm{pO}_{2}$ between 10 and 60 $\mathrm{mmHg}$. Bacteroids extracted from soybean (Fig. $1 b$ ) or pea nodules gave similar results.

The dissolved $\mathrm{O}_{2}$ concentration remained fairly constant, throughout a 15 min experiment, for the different initial values of $\mathrm{pO}_{2}$ in the presence of glucose (Fig. 2) or sucrose. Thus, in experiments performed with a gas phase in the presence of these two substrates, it was possible to provide $\mathrm{O}_{2}$ steady-state conditions for bacteroid respiration. In contrast, $\mathrm{O}_{2}$ consumption was stimulated by succinate and the concentration of free dissolved $\mathrm{O}_{2}$ dropped rapidly, reaching about $50 \%$ of the initial concentration after $15 \mathrm{~min}$. In the presence of glucose, acetylene reduction proceeded linearly with time during $15 \mathrm{~min}$ for the lowest $\mathrm{O}_{2}$ tensions (Fig. 2). Acetylene reduction did not occur when the $\mathrm{pO}_{2}$ was $50 \mathrm{mmHg}$.

\section{Acetylene reduction in the presence of leghaemoglobin}

The changes in absorption spectra occurring during the deoxygenation of leghaemoglobin by bacteroids from French-bean (Fig. $3 a$ ) and soybean (Fig. $3 b$ ) in experiments performed with no gas phase showed that deoxygenation was a sigmoidal phenomenon both for the 


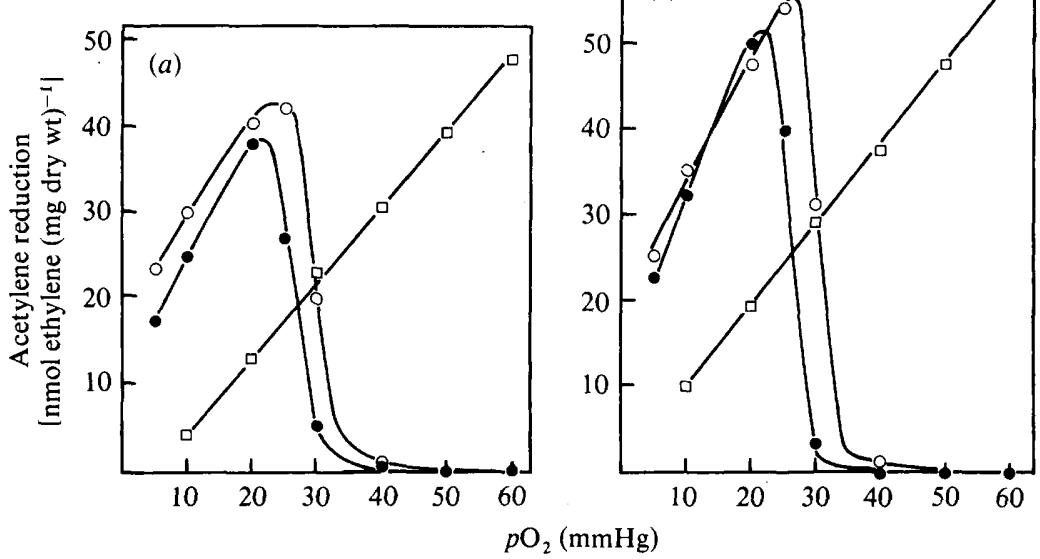

Fig. 1. Acetylene reduction by French-bean $(a)$ and soybean $(b)$ bacteroids as a function of $p \mathrm{O}_{2}$ in the gas phase. Incubation mixtures $(2 \mathrm{ml})$ contained $50 \mathrm{~mm}$ glucose $(O)$, sucrose $(O)$ or succinate ( $\square$ ) and bacteroids (20 mg dry wt) in phosphate buffer $(25 \mathrm{~mm}, \mathrm{pH} 7.4)$. The vials were shaken (140 rev. $\mathrm{min}^{-1}$ ) at $30^{\circ} \mathrm{C}$ for $10 \mathrm{~min}$.

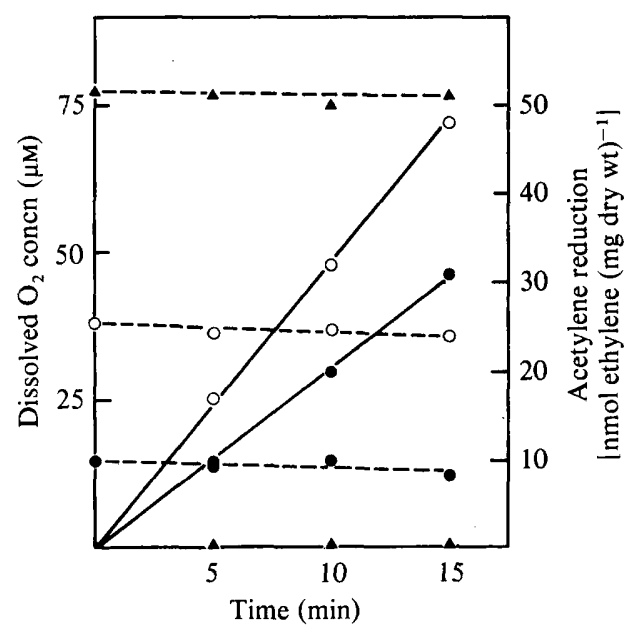

Fig. 2. Time course of acetylene reduction by French-bean bacteroids ( - ) and dissolved $\mathrm{O}_{2}$ concentration in the incubation mixtures (--). The initial $\mathrm{pO}_{2}$ values in the gas phase were 10 (O), $25(\mathrm{O})$ and $50(\Delta) \mathrm{mmHg}$; the corresponding dissolved $\mathrm{O}_{2}$ concentrations were 16,39 and $78 \mu \mathrm{M}$, respectively. Incubation mixtures $(2 \mathrm{ml})$ contained $50 \mathrm{~mm}$-glucose and bacteroids $(19 \mathrm{mg}$ dry $w t)$ in phosphate buffer $(25 \mathrm{~mm}, \mathrm{pH} 7.4)$. The vials were shaken $\left(140\right.$ rev. $\left.\min ^{-1}\right)$ at $30^{\circ} \mathrm{C}$.

increase in absorbance at $562 \mathrm{~nm}$ and the decrease at $576 \mathrm{~nm}$. The leghaemoglobin deoxygenation rate was always lower in the presence of glucose or sucrose than with succinate.

The results of a typical experiment conducted with French-bean bacteroids at different low concentrations of dissolved $\mathrm{O}_{2}$, with leghaemoglobin, are given in Fig. 4. In the presence of glucose or sucrose, acetylene reduction activity was stimulated with free dissolved $\mathrm{O}_{2}$ in the range to 1 to $5 \mathrm{nM}$ and strongly inhibited at higher concentrations (Fig. $4 a$ ). With succinate, ethylene formation increased at $\mathrm{O}_{2}$ concentrations between 5 and $10 \mathrm{nM}$ and then remained relatively constant at higher concentrations. The same optimal acetylene reduction rate $[5$ to $6 \mathrm{nmol}$ ethylene $\min ^{-1}(\mathrm{mg} \text { dry wt })^{-1}$ ] was reached with $100 \mathrm{nM}-\mathrm{O}_{2}$ in the presence of 


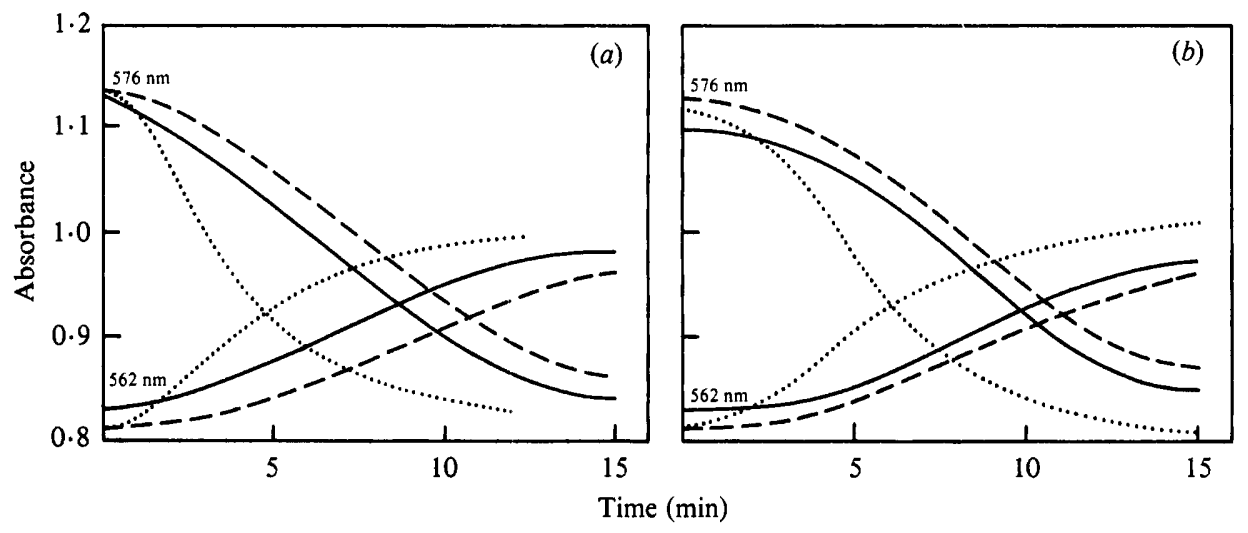

Fig. 3. Time course of leghaemoglobin deoxygenation by French-bean ( $a$ ) and soybean $(b)$ bacteroids monitored spectrophotometrically at 562 and $576 \mathrm{~nm}$. Reaction mixtures $(4 \mathrm{ml})$, in stoppered cuvettes, contained $10 \mathrm{mM}$ glucose (-), sucrose (--) or succinate $(\cdots), 75 \mu \mathrm{M}$-leghaemoglobin and bacteroids ( $1 \mathrm{mg}$ dry wt) in phosphate buffer $(25 \mathrm{mM}, \mathrm{pH} 7.4)$. The initial free $\mathrm{O}_{2}$ concentration was $1 \mu \mathrm{M}$.
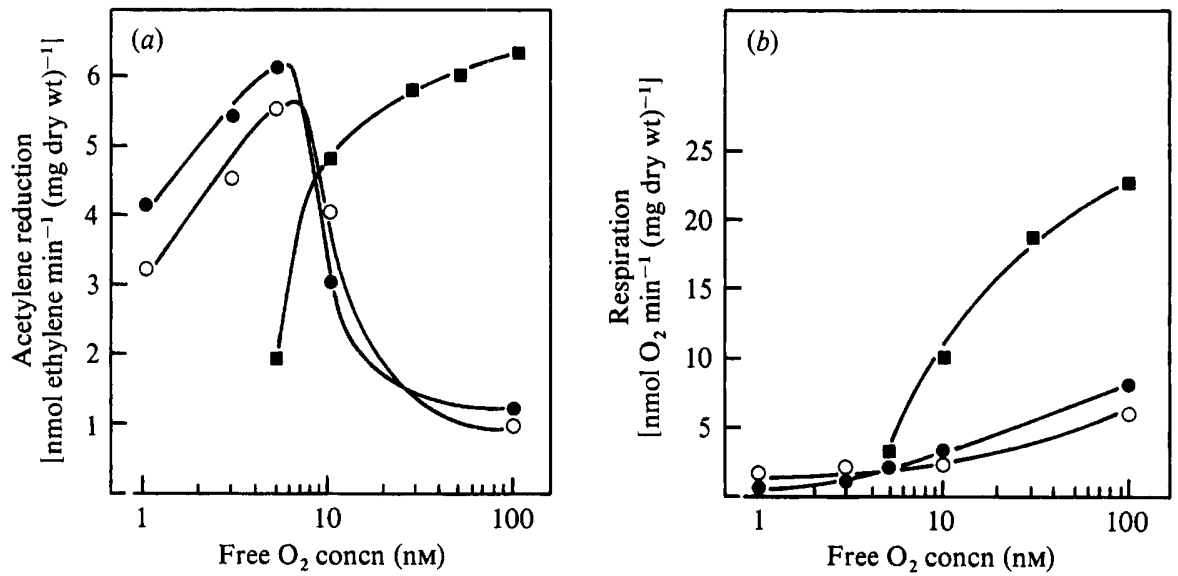

Fig. 4. Acetylene reduction $(a)$ and $\mathrm{O}_{2}$ consumption $(b)$ by French-bean bacteroids at low dissolved $\mathrm{O}_{2}$ concentration. The reaction solution $(4 \mathrm{ml})$ contained $10 \mathrm{mM}$ glucose $(O)$, sucrose $(O)$ or succinate $(\square)$, $82 \mu \mathrm{M}$-leghaemoglobin and bacteroids (1.2 $\mathrm{mg}$ dry wt) in phosphate buffer (25 mM, pH 7.4).
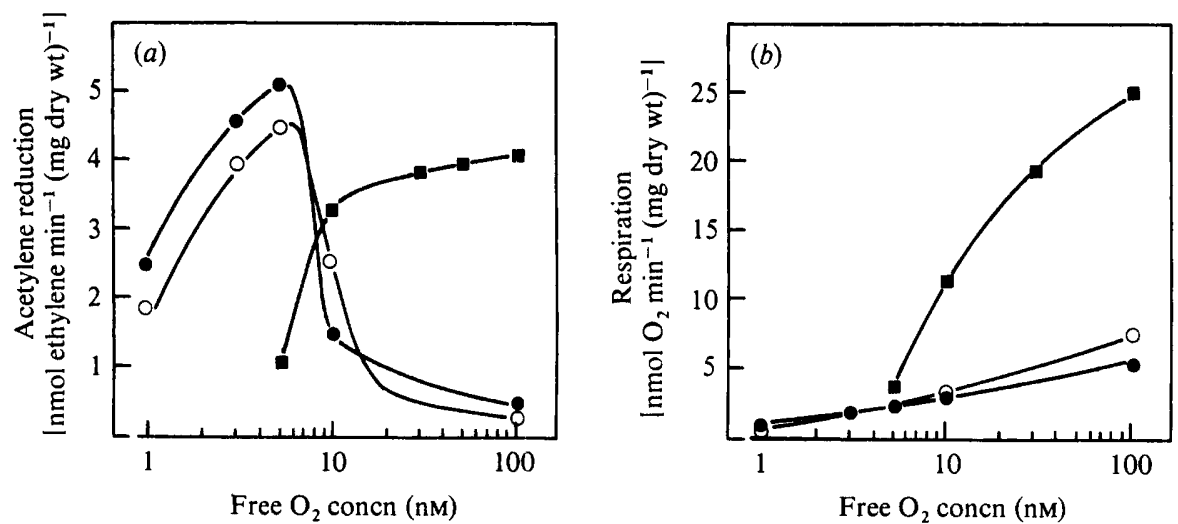

Free $\mathrm{O}_{2}$ concn (nM)

Fig. 5. Acetylene reduction $(a)$ and $\mathrm{O}_{2}$ consumption $(b)$ by soybean bacteroids at low dissolved $\mathrm{O}_{2}$ concentration. Experimental conditions were as described in Fig. 4. 


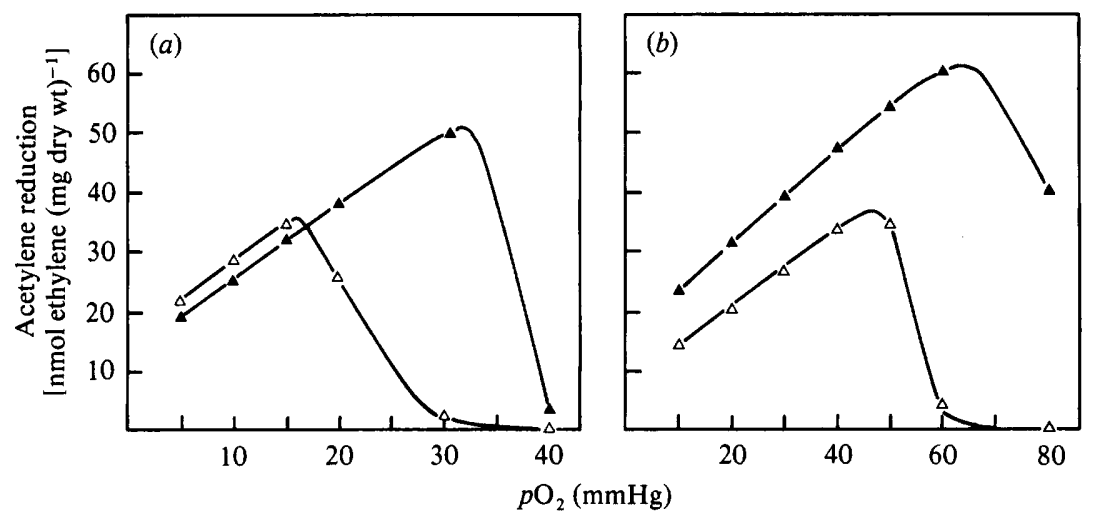

Fig. 6. Effect of $\mathrm{pO}_{2}$ on acetylene reduction activity of French-bean bacteroids extracted from 12-d-old $(A)$ or 24-d-old $(\Delta)$ nodules. Incubation mixtures $(2 \mathrm{ml})$ contained $50 \mathrm{~mm}$ glucose $(a)$ or succinate $(b)$ and bacteroids $(20 \mathrm{mg}$ dry wt) in phosphate buffer $(25 \mathrm{~mm}, \mathrm{pH} 7 \cdot 4)$. The vials were shaken $(140 \mathrm{rev}$. $\min ^{-1}$ ) at $30^{\circ} \mathrm{C}$ for $10 \mathrm{~min}$.

succinate as with $5 \mathrm{nM}-\mathrm{O}_{2}$ in the presence of glucose or sucrose. In all cases the rate of acetylene reduction remained linear with time for at least $10 \mathrm{~min}$. In the range of 1 to 100 nM-O $\mathrm{O}_{2}$, respiration was enhanced 3 -fold with glucose or sucrose (Fig. $4 b$ ); in contrast, $\mathrm{O}_{2}$ uptake increased $8 \cdot 5$-fold in the presence of succinate when the $\mathrm{O}_{2}$ concentration was increased from 5 to $100 \mathrm{nM}$. Similar results were obtained with bacteroids extracted from soybean root nodules (Fig. $5 a, b$ ).

\section{Bacteroid $\mathrm{O}_{2}$ sensitivity in relation to nodule age}

The effect of $\mathrm{pO}_{2}$ on acetylene reduction activity was studied with French-bean bacteroids isolated from 12- and 24-d-old nodules. Glucose or succinate was added as respiratory substrate in experiments with a gas phase (Fig. 6). In both cases, acetylene reduction activity was lower for the older bacteroids, but the decline was always less marked with glucose than with succinate. Moreover, the $\mathrm{O}_{2}$ tension required for optimal nitrogenase activity was shifted to a lower $\mathrm{pO}_{2}$ with both glucose (from 30 to $15 \mathrm{mmHg}$ ) and succinate (from 60 to 45 $\mathrm{mmHg}$ ). For both substrates, the $\mathrm{O}_{2}$ tensions which gave the highest ethylene formation with young bacteroids completely inhibited the activity of old bacteroids.

French-bean bacteroids extracted from 25 -d-old nodules and kept in liquid $\mathrm{N}_{2}$ for $15 \mathrm{~d}$ showed a similar increase in sensitivity to $\mathrm{O}_{2}$.

\section{DISCUSSION}

Sucrose and glucose were able to provide energy for acetylene reduction by bacteroids isolated from root nodules of different legumes. This property was observed with bacteroids belonging to both the fast- and slow-growing groups of Rhizobium. Low $\mathrm{O}_{2}$ tensions were required with both these carbohydrates for acetylene reduction and were critical for optimal activity. These results are similar to those of Rigaud et al. (1973) concerning the ability of glucose to support $\mathrm{N}_{2}$ fixation in anaerobic conditions with $\mathrm{NO}_{3}^{-}$as the terminal electron acceptor. They confirm the suggestion of Bergersen (1977) about a role for hexoses in providing energy and reductant for nitrogenase activity in vivo, although glucose was generally considered to be a poor substrate for bacteroids. Several authors have concluded that different preparations of bacteroids are unable to oxidize glucose (Ronson \& Primrose, 1979; Vries, 1980; Ratcliffe et al., 1980). The presence of a substantial amount of sucrose, provided by the plant, associated with the low $\mathrm{O}_{2}$ tension $(3$ to $30 \mathrm{nM})$ in the nodules 
(Wittenberg et al., 1974), creates optimal conditions for this substrate to play a major role in $\mathrm{N}_{2}$ fixation in vivo. Bacteroids oxidizing these carbohydrates had a lower $\mathrm{O}_{2}$ requirement than those oxidizing succinate for the same level of $\mathrm{N}_{2}$ fixation. The presence of leghaemoglobin in experiments with no gas phase confirmed this result in that significant acetylene reduction activity was observed for $\mathrm{O}_{2}$ concentrations ( 1 to $5 \mathrm{nM}$ ) lower than those reported in experiments with soybean bacteroids and succinate (Bergersen \& Turner, 1979, 1980). These $\mathrm{O}_{2}$ concentrations are in the range of those determined in the nodules (quoted above). Thus, sucrose and glucose could play a complementary role to leghaemoglobin in the $\mathrm{O}_{2}$ economy of nodules.

When succinate was used as carbon source, the experimental procedure using bacteroid incubations with a gas phase did not generally provide $\mathrm{O}_{2}$ steady-state conditions (Trinchant \& Rigaud, 1979), except during a short period of time (Laane et al., 1978). The low bacteroid $\mathrm{O}_{2}$ consumption observed in the presence of glucose or sucrose permitted an equilibrium between $\mathrm{O}_{2}$ uptake and $\mathrm{O}_{2}$ dissolution from the gas phase to be maintained for a significant period of time. Thus, in giving an $\mathrm{O}_{2}$ steady-state, glucose and sucrose provided accurate conditions for $\mathrm{O}_{2}$ utilization by bacteroids in gas phase assays which were more convenient for ethylene determination.

To explain the discrepancy between our results and those commonly reported in the literature about sugar utilization by bacteroids in vitro, a major role for $\mathrm{O}_{2}$ may be suggested. Sucrose and glucose were able to support acetylene reduction in a very narrow range of $\mathrm{O}_{2}$ concentrations in assays conducted with a gas phase $(7.5$ to $39 \mu \mathrm{M})$ or with no gas phase after addition of leghaemoglobin ( 1 to $5 \mathrm{nM}$ ). Higher $\mathrm{O}_{2}$ concentrations completely abolished $\mathrm{N}_{2}$ fixation but were optimal when succinate was used. This loss of activity observed with carbohydrates was not caused by an inactivation of nitrogenase by $\mathrm{O}_{2}$, since acetylene reduction was completely restored by subsequent addition of succinate (Trinchant \& Rigaud, 1979).

The bacteroid concentration was another critical factor. On average, $1 \mathrm{mg}$ (dry wt) of bacteroids required $1.5 \mu \mathrm{M}$ dissolved $\mathrm{O}_{2}$ for optimal acetylene reduction when sucrose or glucose was supplied in gas phase experiments. Thus, inadequate conditions such as the dilution of bacteroid suspensions or the use of old bacteroids, in increasing the sensitivity to $\mathrm{O}_{2}$, could also explain the previous failure to observe acetylene reduction when sucrose or glucose was used as substrate.

This research received financial support from the Centre National de la Recherche Scientifique.

\section{REFERENCES}

Antoniw, L. D. \& Sprent, J. I. (1978). Primary metabolites of Phaseolus vulgaris nodules. Phytochemistry 17, 675-678.

APpleBY, C. A. (1969). The separation and properties of low-spin (haemochrome) and native, high-spin forms of leghaemoglobin from soybean nodule extracts. Biochimica et biophysica acta 189, 267279.

BACH, M. K., Magee, W. E. \& BurRis, R. H. (1958). Translocation of photosynthetic products to soybean nodules and their role in nitrogen fixation. Plant Physiology 33, 118-124.

BERGERSEN, F. J. (1967). Some properties of nitrogenfixing breis prepared from soybean root nodules. Biochimica et biophysica acta 130, 304-312.

Bergersen, F. J. (1971). Biochemistry of symbiotic nitrogen fixation in legumes. Annual Review of Plant Physiology 22, 121-140.

BERGERSEN, F. J. (1974). Formation and function of bacteroids. In The Biology of Nitrogen Fixation, pp.
473-498. Edited by A. Quispel. Amsterdam: NorthHolland Publishing Co.

Bergersen, F. J. (1977). Physiological chemistry of dinitrogen fixation by legumes. In $A$ Treatise on Dinitrogen Fixation. Section III: Biology, pp. 519-555. Edited by R. W. F. Hardy \& W. S. Silver. New York:Wiley-Interscience.

Bergersen, F. J. \& Turner, G. L. (1967). Nitrogen fixation by the bacteroid fraction of breis of soybean root nodules. Biochimica et biophysica acta 141, 507-515.

Bergersen, F. J. \& Turner, G. L. (1973). Kinetic studies of nitrogenase from soybean root nodule bacteroids. Biochemical Journal 131, 61-75.

Bergersen, F. J. \& Turner, G. L. (1975). Leghaemoglobin and the supply of $\mathrm{O}_{2}$ to nitrogen-fixing root nodule bacteroids: studies of an experimental system with no gas phase. Journal of General Microbiology 89, 31-47.

Bergersen, F. J. \& Turner, G. L. (1979). Systems 
utilizing oxygenated leghemoglobin and myoglobin as sources of free dissolved $\mathrm{O}_{2}$ at low concentrations for experiments with bacteria. Analytical Biochemistry 96, 165-174.

Bergersen, F. J. \& Turner, G. L. (1980). Properties of terminal oxidase systems of bacteroids from root nodules of soybean and cowpea and of $\mathrm{N}_{2}$-fixing bacteria grown in continuous culture. Journal of General Microbiology 118, 235-252.

Bergersen, F. J., Turner, G. L. \& Appleby, C. A. (1973). Studies of the physiological role of leghaemoglobin in soybean root nodules. Biochimica et biophysica acta 292, 271-282.

Hardy, R. W. F., Holsten, R. D., Jackson, E. K. \& BuRNS, R. C. (1968). The acetylene-ethylene assay for $\mathrm{N}_{2}$ fixation: laboratory and field evaluation. Plant Physiology 43, 1185-1207.

LAane, C., HaAker, H. \& Veeger, C. (1978). Involvement of the cytoplasmic membrane in nitrogen fixation by Rhizobium leguminosarum bacteroids. European Journal of Biochemistry 87, 147-153.

Puppo, A. \& Rigaud, J. (1975). Indole-3-acetic acid (IAA) oxidation by leghemoglobin from soybean nodules. Physiologia plantarum 35, 181-185.

Ratcliffe, H. D., Drozd, J. W., Bull, A. T. \& DANIEL, R. M. (1980). Energy coupling in soybean bacteroids. FEMS Microbiology Letters 8, 111-115.

Rigaud, J. (1976). Effet des nitrates sur la fixation d'azote par les nodules de Haricot (Phaseolus vulgaris L.). Physiologie végétale 14, 297-308.

RIGAUD, J. \& PUPPo, A. (1975). Indole-3-acetic acid catabolism by soybean bacteroids. Journal of General Microbiology 88, 223-228.
Rigaud, J., Bergersen, F. J., Turner, G. L. \& DANIEL, R. M. (1973). Nitrate-dependent anaerobic acetylene-reduction and nitrogen-fixation by soybean bacteroids. Journal of General Microbiology 77, 137-144.

Ronson, C. W. \& Primrose, S. B. (1979). Carbohydrate metabolism in Rhizobium trifolii: identification and symbiotic properties of mutants. Journal of General Microbiology 112, 77-88.

Singh, R., Sidhu, P. S., Vadhera, S., Sital, J. S. \& BhAtia, I. S. (1980). Extracellular invertase of Rhizobium japonicum and its role in free sugar metabolism in the developing root nodules of Sesbania grandiflora. Physiologia plantarum 48, 504-508.

Streeter, J. G. \& Bosler, M. E. (1976). Carbohydrates in soybean nodules: identification of compounds and possible relationships to nitrogen fixation. Plant Science Letters 7, 312-329.

Trinchant, J. C. \& Rigaud, J. (1979). Sur les substrats énergétiques utilisés, lors de la réduction de $\mathrm{C}_{2} \mathrm{H}_{2}$, par les bactéroïdes extraits des nodosités de Phaseolus vulgaris L. Physiologie végétale 17, 547-556.

VRIES, G. E. (1980). Transport of sugars and organic acids in Rhizobium leguminosarum and their role in symbiosis. Thesis, University of Leiden, The Netherlands.

Wittenberg, J. B., Bergersen, F. J., Appleby, C. A. \& TURner, G. L. (1974). Facilitated oxygen diffusion. The role of leghemoglobin in nitrogen fixation by bacteroids isolated from soybean root nodules. Journal of Biological Chemistry 249, 4057-4066. 